\title{
Supporting infrastructures and research reactors: status, needs and international cooperation, IAEA ICERR (International CEntres based on Research Reactors) and IGORR (International Group on Research Reactors), FP7 and H2020 JHR access rights
}

\author{
Gilles Bignan ${ }^{1}$ and Jean-Yves Blanc ${ }^{2, *}$ \\ ${ }^{1}$ Department for Reactor Studies, CEA, Bdg 707, CEA Cadarache, 13108 Cadarache, France \\ 2 Nuclear Energy Division, CEA, Bdg 121, CEA Saclay, 91191 Gif-sur-Yvette, France
}

Received: 5 April 2019 / Accepted: 4 June 2019

\begin{abstract}
The panorama of research reactors in the world is at a turning point, with many old ones being shutdown, a very few new ones under construction and many newcomer countries interested to get access to one or to build one domestic research reactor or zero-power reactor. In this evolving context, several actions have been set up to answer this international collaboration need: the IAEA has launched the ICERR initiative, the OECD/NEA is proposing the P2M joint project proposal. In France, the Jules Horowitz Reactor (JHR), under construction at CEA Cadarache, within an International Consortium, will be one of the few tools available for the industry and research in the next decades. The paper presents some update of its construction, its experimental capacities and the European support through FP7 and H2020 tools. This paper provides also some insights of international tools (ICERR, P2M) and about the International Group on Research Reactors (IGORR) and how they complement or interact with the JHR.
\end{abstract}

\section{Introduction}

The panorama of experimental research reactors has recently evolved, with the shutdown of several important Material Testing Reactors (MTR):

- the Osiris reactor in CEA, France at the end of 2015;

- the Japan Material Test Reactor, by mid-2017;

- and the Halden Boiling Water Reactor, in Norway, in June 2018.

A quick look at some major remaining MTRs in operation today indicates that several of them are quite old: ATR (USA, 1967), MIR and SM3 (Russia, 1967 \& 1961 respectively), BR2 (Belgium, 1962), HFR (Netherlands, 1961), although LVR-15 (Czech Republic, 1995) and the TRIGA in Pitesti (Romania, 1980) are younger. The probability of final shutdown in the next $10-20$ years of the facilities built in the sixties appears very high.

To cope with that, few projects of new MTRs with a respectable power are really under construction: JHR at CEA Cadarache, France, MBIR (sodium-cooled, fastneutron reactor) at RIAR, Dimitrovgrad, Russia, and a new reactor to replace HFETR of NPIC near Chengdu, China. Most importantly, only JHR and MBIR will present

\footnotetext{
* e-mail: jean-yves.blanc@cea.fr
}

both an important experimental capacity and the possibility of international access. In the USA, the decision last year to launch detailed design studies of the Versatile Test Reactor (VTR) project means also good news.

At the same time, several newcomer countries are contemplating the possibility of buying a small research reactor, like Jordan, which started the Jordan Research and Training Reactor (5 MW) by December 2016, or Saudi Arabia, where a small $30 \mathrm{~kW}$ reactor is under construction at KACST, Riyadh.

In this evolving context, several initiatives have been launched to increase the international cooperation around the remaining facilities.

\section{The Jules Horowitz Reactor}

\subsection{Generalities}

A detailed presentation of experimental capacities of the Jules Horowitz Reactor (JHR) could be found in reference [1]. The JHR is under construction on the CEA Cadarache site (Fig. 1). It will be operated as an international user's facility for materials and fuel irradiations for the nuclear industry or research institutes, but it has a second objective to produce medical radioisotopes [2]. The detail of the pile block manufacturing has been presented recently [3]. 


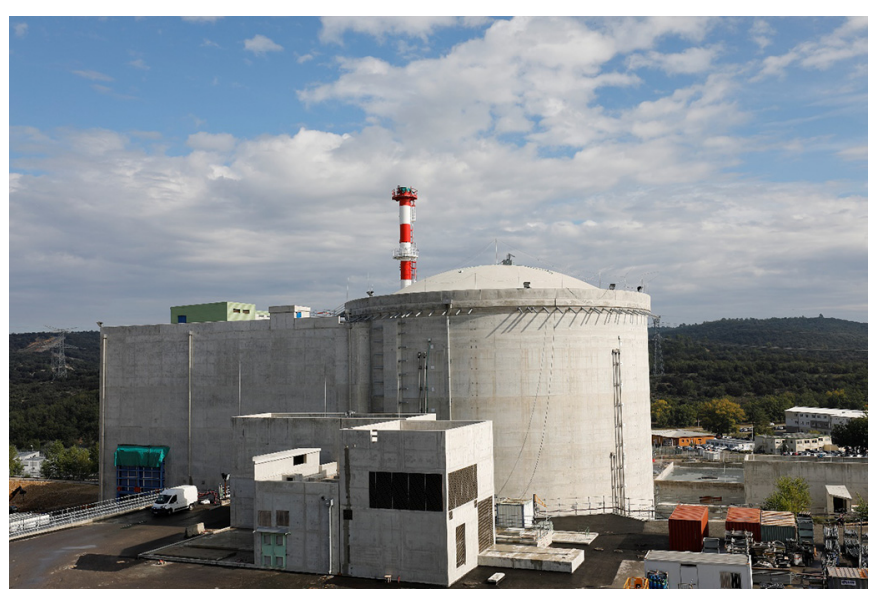

Fig. 1. Jules Horowitz Reactor - October 2017.

The construction is made within the framework of an international consortium: CEA, EdF, AREVA SA, Framatome, Technicatome (France); European Commission with JRC as Observers; CIEMAT (Spain); SCK-CEN (Belgium); VTT (Finland); UJV (Czech Republic); Studsvik AB (Sweden); NNL (UK); DAE (India); IAEC (Israel). Some contacts are ongoing with other foreign entities to discuss their potential interest to join the consortium, or to participate in future programmes.

\subsection{General description}

The JHR is a $100 \mathrm{MWth}$ pool-type reactor with a compact core cooled by a slightly pressurized primary circuit. The nuclear facility comprises (Fig. 2) a reactor building with all systems dedicated to the reactor and experimental devices and an auxiliary building to support both reactor and experimental devices operation, including hot cells, storage pools and laboratories.

The facility is designed to operate 20 experiments simultaneously. Locations for irradiation are either in the core or in the beryllium reflector.

- 10 locations within the core will provide for a high fast neutron flux $\left(5.5 \times 10^{14} \mathrm{n} . \mathrm{cm}^{-2} \cdot \mathrm{s}^{-1}\right.$ above $1 \mathrm{MeV}$ corresponding to a maximum of material damage $16 \mathrm{dpa} /$ year); - about 20 locations in the beryllium reflector will provide a high thermal neutron flux (up to $3.5 \times 10^{14} \mathrm{n} . \mathrm{cm}^{-2}$. $\mathrm{s}^{-1}$ corresponding to about $0.1 \mathrm{dpa} /$ year). Material experiments requiring a low ageing rate, such as the pressure vessel steel, will be installed inside the reflector.

- four to six water channels through the reflector will be equipped with displacement devices to control accurately the distance to the core and therefore the irradiation flux (for an accurate stable power, for power ramps, or for power cycling, etc.).

The JHR will also provide for non-destructive examinations with:

- a coupled gamma-scanning and X-ray tomography bench located in the reactor pool;

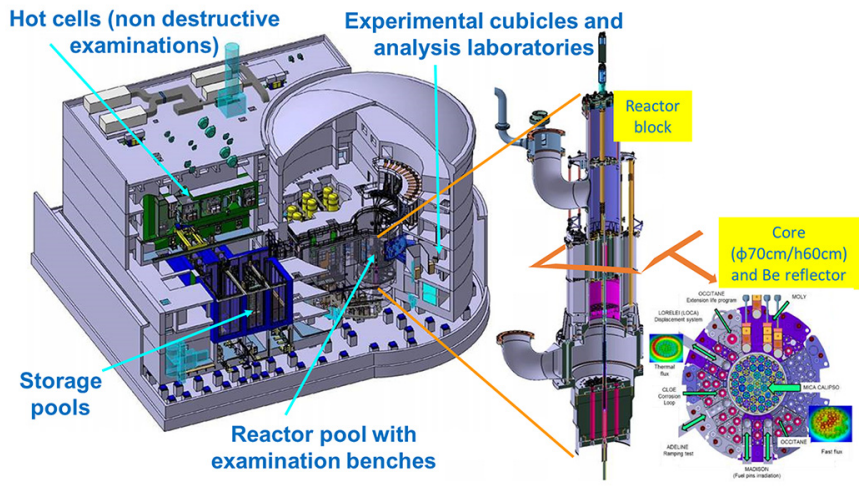

Fig. 2. General structure of the JHR.

- a similar bench in the storage pool of the nuclear auxiliary building;

- a neutron imaging system bench located in the reactor pool.

The other post-irradiation examinations will be performed at the nearby LECA-STAR hot laboratory for fuel PIE, or at the LECI hot lab for materials PIE or at the customer hot laboratory.

\subsection{Main experimental devices}

Several test devices are under design or mock-up manufacturing. Some of them will be available for the start-up of the reactor (MADISON, ADELINE, MICA), the others being part of a second fleet (LORELEI, OCCITANE, CLOE):

- MADISON for LWR fuel testing under nominal conditions, (evolution of the fuel micro structure, clad corrosion, fission gas releases, etc.);

- ADELINE for LWR fuel under off-normal situations, especially for power ramp testing;

- LORELEI for LWR fuel under large break LOCA conditions;

- MICA could perform in-core irradiation on vessel or clad materials (tensile, Charpy, CT samples, etc.);

- OCCITANE will be dedicated to ageing of pressure vessel steel;

- CLOE will be dedicated to corrosion experiments (IASCC) on stainless steel components.

Other test devices are also considered, such as the RISHI loop, cooled by circulating $\mathrm{Na}$, for material irradiation, but all these loops will not be all implemented at JHR early years of operation, but progressively. Some devices are also designed for the start-up phase of the reactor, such as the neutron start-up sources, the neutron poison absorbers, the start-up instrumentation devices and the monitoring devices [4].

\subsection{Preparing the experimental programmes}

Several actions are running to gather a scientific community around JHR and to prepare the first experimental 
programmes once JHR in operation:

- The Consortium established three Working Groups to prepare the fuel irradiations, the material irradiations and for technology issues linked to experimental devices.

- A JHR scientific and technical seminar is organized every year.

- In April 2019, a first JHR school was added to the Seminar. Thirteen young scientists/engineers from the consortium members get lectures about the needs of MTR to answer key-questions about fuel and material behaviour under irradiation and create a first forum of scientific exchanges.

Some other actions are described in the following paragraphs. This list is not exhaustive.

\section{The European support to JHR: FP7 and H2020 JHR access rights}

The European Commission has been supportive of the JHR access from the beginning. Its financial support has been conveyed since 2009 using several contracts with the Joint Research Centre and the DG-RTD, through the JHRCollaborative Project (2009-2010) and using FP7 and H2020 frameworks.

By mid-2018, the European Commission has secured $5.15 \%$ of the guaranteed access to irradiation capacity. It makes the EC the larger foreign contributor to the JHR, because seven bilateral foreign partners have taken $2 \%$ each and India $3 \%$.

This support will continue with three new actions:

- a complementary funding of Euratom to increase its access rights up to $6 \%$ (Indicated on the last $\mathrm{H} 2020$ Euratom call as OA6);

- an interest of the Joint Research Centre (JRC) to develop together an experimental test loop that would fit current and future requirements for material and/or fuel tests in the JHR, to be confirmed within the 2021-2025 Euratom financial allocation;

- a Coordinated Support Action (CSA) to build a roadmap for the use of Euratom Access Rights for the benefit of EC Member States to get access to JHR Experimental capacity.

The CEA is very thankful to the European Commission for its continuing support.

\section{The IAEA initiative: ICERR (International CEntres based on Research Reactors)}

\subsection{ICERR concept}

In 2014, IAEA Director General Yukiya Amano approved a new initiative, namely the IAEA designated International Centre based on Research Reactors (ICERR), which will help Member States to gain access to international research reactor infrastructure.

The Terms of Reference (See IAEA web site) for designation of an ICERR give more details on this concept: "The proposed scheme of "IAEA designated International Centre based on Research Reactor" (ICERR scheme) is intended to help IAEA Member States gain timely access to relevant nuclear infrastructure based on RRs and their ancillary facilities. ICERRs will make available their RRs and ancillary facilities and resources to organizations/ institutions of IAEA Member States seeking access to such nuclear infrastructure (named Affiliates). For Affiliates, ICERRs will provide an opportunity to access RR capabilities much sooner and, probably, at a lower cost. This availability may obviate the need, for example, to build a new RR in their country.

The implementation of the ICERR scheme will also contribute to enhance the utilization of some existing RR facilities [...]. On the other hand, an ICERR could benefit, for example, from additional scientific and/or technical resources made available by the Affiliate (e.g. Secondees) and by the increase of its international visibility."

In answer to this IAEA initiative, several entities submitted their candidacy, and after an expert audit, the ICERR label was awarded to:

- CEA Saclay and Cadarache, with JHR and ancillary facilities, i.e. LECA-STAR and LECI hot labs, EOLEMINERVE, ISIS and ORPHEE reactors, in September 2015;

- the RIAR in Dimitrovgrad, Russian Federation, in 2016;

- SCK-CEN in Belgium, in 2017;

- INL and ORNL, in the USA in 2017.

A few other candidacies are foreseen in the coming years.

\subsection{Implementation of ICERR on the JHR}

Today, CEA has signed seven bilateral agreements with the following affiliates:

- Jozef Stefan Institute, Slovenia;

- CNESTEN, Morocco;

- CNSTN, Tunisia;

- BATAN, Indonesia;

- COMENA, Algeria;

- JAEC, Jordan;

- FANR, United Arab Emirates.

IAEA is not engaged of these bilateral agreements but is acting as a facilitator. For instance, IAEA could, in some cases, provide funding for travel and accommodation expenses through its Technical Cooperation tools.

The technical content and the implementation of these agreements are adapted to the needs and interests of the different partners. It could consist, as examples, in sending a secondee to CEA Saclay or Cadarache for hands-on training, sending CEA engineers to help for implementing neutron beam activities on an affiliate reactor, analysis by CEA of an affiliate's safety report, measurement campaign inside an affiliate's reactor, participation of foreign scientists to CEA experimental campaigns, co-tutorship of a PhD, exchanges on nuclear instrumentation, core physics calculation of the affiliate reactor, etc.

The ICERR concept is very interesting for JHR future programmes, because it constitutes a second circle of partners around the JHR, the first circle being the members of the Consortium. It also gives to the CEA an opportunity of access to foreign facilities and therefore to increase international exchanges and relationships. 


\section{The OECD/NEA initiative: the $\mathrm{P} 2 \mathrm{M}$ joint project proposal}

During many years, the nuclear community extensively used the Halden reactor for experimental programmes, under the aegis of the Nuclear Energy Agency of the OECD. Its premature and definite shutdown last year induced a reduced experimental capability available to answer the needs of companies willing to develop nuclear fuel and materials. In 2018, the OECD/NEA [5] held several workshops or technical meetings, gathering its Nuclear Science Committee (NSC) and Committee on the Safety of Nuclear Installations (CSNI) members, for providing the basics of a new vision for building international joint research projects, as they are considered as an efficient way for improving the R\&D knowledge and maintaining skilled teams. For that aim, an implementation, networking several infrastructures (MTRs and hot cell laboratories for post-irradiation examinations) on a same program, is clearly a relevant approach.

With this objective, the P2M R\&D program, proposed to the OECD/NEA by a "core group" gathering SCK $\bullet C E N$, CEA and EDF, is currently the first and the most developed proposal. It aims at discriminating, ranking and quantifying mechanisms that appear in a LWR fuel rod during any type of power transients, with a focus on those provoking a moderate to high load on the clad. This focus includes power levels initiating a central melting of the fissile material. A first step (called "Task 1") includes two tests and will be implemented in the BR2 MTR thanks to the PWC-CD boiling capsule. It aims at obtaining a predetermined molten volume fraction at the hottest part of the experimental rod. Then this final status will be analysed by non-destructive and destructive examinations at the LHMA (SCK•CEN) and LECA-STAR (CEA Cadarache) respectively. Both tests are planned fall 2020 and fall 2021 respectively, and Task 1 is expected to be completed by mid-2023.

\section{The IGORR: International Group on Research Reactors}

This International Group, started in 1989, organizes about every year and a half an international conference on research reactors. IGORR-19 was held in Jordan in March 2019 and IGORR-20 is foreseen in RIAR, Dimitrovgrad, Russia, during the first week of September 2020. It represents a very good forum where representatives of research reactors around the world can discuss the challenges of their field. The participation, from 17 papers and 52 attendees from 10 countries in 1989, increased thirty years later to around 210 papers or posters and 230 attendees from 40 countries, showing the growing interest for this forum [6].

IGORR is often jointly organized with RRFM, the European Nuclear Society conference on Research Reactor Fuel Management, started in 1997. Sometimes IGORR also hosted some embedded IAEA Technical Meeting on ageing management issues (e.g. in 2013), on Low Power Research Reactor Utilization (e.g. in 2014) or an IAEA Workshop on Safety Reassessment of Research Reactors (e.g. in 2017).

This contributes to give the maximum synergy between entities working on research reactors.

\section{Conclusions}

In a worldwide landscape of ageing research reactors, the future would be limited to a few new facilities open to international programmes. JHR ambitions to be one of these. As its construction is progressing, it is of vital importance to start with the best test devices and the most adapted to the customers' needs.

To reach these targets, CEA designed JHR from the start as an international user's facility. This is particularly true when looking at the Members of its Consortium, which include many European countries, plus India and Israel. Thanks to the important and continuing support of the European Commission, through its FP7 and H2020 powerful tools, the JHR will offer access to European countries. Moreover, several other international initiatives are also well adapted to enhance these collaborations, such as the IAEA ICERR label, the P2M project of the OECD/ NEA, and the IGORR forum.

\section{References}

1. C. Gonnier, J.-P. Chauvin, G. Bignan, B. Maugard, Update of the JHR experimental capacity and first orientations for the experimental programs, in IGORR 2019

2. J.-P. Coulon, M. Antony, C. Chapuis, Production of radioisotopes at Jules Horowitz Reactor, in RRFM-IGORR 2019

3. F. Duquesnoy, F. Witters, P. Parraud, Jules Horowitz Reactor (JHR): Manufacture of the reactor pile-block, in IGORR 2019

4. J.-P. Coulon, Jules Horowitz Reactor (JHR): start-up equipments and experimental utilities, in IGORR 2019

5. D.P. Parrat, Networking multinational fuel and materials testing capacities for science, safety and industry: The P2M Joint Project Proposal in the frame of the OECD/NEA, in IGORR 2019

6. D. Selby, K. Rosenbalm, IGORR: The First Twenty-Five Years, in RRFM-IGORR 2016

Cite this article as: Gilles Bignan, Jean-Yves Blanc, Supporting infrastructures and research reactors: status, needs and international cooperation, IAEA ICERR (International CEntres based on Research Reactors) and IGORR (International Group on Research Reactors), FP7 and H2020 JHR access rights, EPJ Nuclear Sci. Technol. 6, 26 (2020) 